\title{
Gesso e calcário aumentam a produtividade e amenizam o efeito do déficit hídrico em milho e soja ${ }^{1}$
}

\author{
Renan Ricardo Zandoná2, Amauri Nelson Beutler², \\ Giovane Matias Burg${ }^{2}$, Caroline Farias Barreto 2 , Marcelo Raul Schmidt ${ }^{2}$
}

\begin{abstract}
Gypsum and lime increase soybean and maize yield and decrease drought stress

During the maize and soybean cultivation process, water deficit occurs frequently and can reduce grain yield. Gypsum can be used to mitigate yield losses. This study aimed to evaluate the influence of gypsum application, with and without lime, on soil chemical properties and maize and soybean yield, in a no-till system. The experimental design was completely randomized, with six gypsum doses $\left(0 \mathrm{tha}^{-1}, 0.5 \mathrm{tha}^{-1}, 1 \mathrm{tha}^{-1}, 2 \mathrm{tha}^{-1}, 4 \mathrm{tha}^{-1}\right.$ and $8 \mathrm{t} \mathrm{ha}^{-1}$ ), lime application and four replications, for maize. For soybean, a $6 \times 2$ factorial scheme, with six gypsum doses $\left(0 \mathrm{t} \mathrm{ha}^{-1}, 0.5 \mathrm{t} \mathrm{ha}^{-1}, 1 \mathrm{tha}^{-1}, 2 \mathrm{tha}^{-1}, 4 \mathrm{t} \mathrm{ha}^{-1}\right.$ and $\left.8 \mathrm{tha}^{-1}\right)$, with and without lime application, and four replications was used. Soil chemical attributes and maize and soybean grain yield were evaluated. Gypsum increases the $\mathrm{Ca}^{2+}$ levels, redistributes $\mathrm{Mg}^{2+}$ to the 10-20 cm and 20-40 cm depth layers and decreases the $\mathrm{Al}^{3+}$ contents in the 20-40 cm layer. Liming increases $\mathrm{pH}$ in the $0-10 \mathrm{~cm}$ depth layer and $\mathrm{pH}$ is not affected by the gypsum application. Gypsum increases maize and soybean grain yield, with response up to the $2 \mathrm{t} \mathrm{ha}^{-1}$ dose, with increments of $9.3 \%$, for maize, and $11.4 \%$ and $11.3 \%$, respectively with and without lime, for soybean.
\end{abstract}

KEY-WORDS: Zea mays L.; Glycine $\max (\mathrm{L}$.$) Merrill; soil$ acidity.

\section{INTRODUÇÃO}

O Brasil é um dos países que tem maior área agrícola cultivada em sistema plantio direto (SPD), com 31,8 milhões de hectares, que correspondem a mais da metade da área agrícola do País (Febrapdp 2012). A acidez do solo é um dos fatores mais limitantes à produtividade das culturas, no mundo (Fageria 2001), sendo a calagem utilizada para a sua correção.

Com a calagem, eleva-se o $\mathrm{pH}$ do solo,

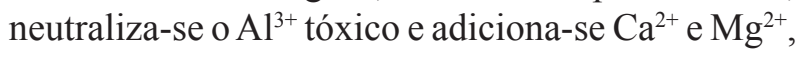

\section{RESUMO}

Durante o cultivo de milho e soja, é comum a ocorrência de déficit hídrico, que pode reduzir a produtividade de grãos. O gesso agrícola pode ser utilizado para mitigar as perdas na produtividade. Este trabalho objetivou avaliar a influência da aplicação de gesso agrícola, com e sem calcário, nos atributos químicos do solo e na produtividade de milho e soja, em sistema plantio direto. $\mathrm{O}$ delineamento experimental foi inteiramente casualizado, com seis doses de gesso $\left(0 \mathrm{t} \mathrm{ha}^{-1}, 0,5 \mathrm{t} \mathrm{ha}^{-1}, 1 \mathrm{t} \mathrm{ha}^{-1}\right.$, 2 t ha ${ }^{-1}, 4$ tha $^{-1}$ e 8 t ha $\left.^{-1}\right)$, aplicação de calcário e quatro repetições, para o milho. Para a soja, utilizou-se esquema fatorial $6 \times 2$, em que os tratamentos foram seis doses de gesso agrícola $\left(0 \mathrm{t} \mathrm{ha}^{-1}\right.$, $\left.0,5 \mathrm{tha}^{-1}, 1 \mathrm{t} \mathrm{ha}^{-1}, 2 \mathrm{t} \mathrm{ha} \mathrm{i}^{-1}, 4 \mathrm{t} \mathrm{ha}^{-1} \mathrm{e} 8 \mathrm{t} \mathrm{ha}^{-1}\right)$, com e sem aplicação de calcário, com quatro repetições. Atributos químicos do solo e a produtividade de grãos de milho e de soja foram avaliados. $\mathrm{O}$ gesso agrícola aumenta os teores de $\mathrm{Ca}^{2+}$, redistribui o $\mathrm{Mg}^{2+}$ para as camadas de $10-20 \mathrm{~cm}$ e $20-40 \mathrm{~cm}$ e diminui os teores de $\mathrm{Al}^{3+}$ na camada de $20-40 \mathrm{~cm}$. A aplicação de calcário aumenta o $\mathrm{pH}$ na camada de $0-10 \mathrm{~cm}$ de profundidade e o $\mathrm{pH}$ não é alterado pela aplicação de gesso agrícola. O gesso agrícola aumenta a produtividade de grãos de milho e de soja, com resposta até a dose de $2 \mathrm{t} \mathrm{ha}^{-1}$, com incrementos de 9,3\%, para o milho, e $11,4 \%$ e $11,3 \%$, respectivamente com e sem calcário, para a soja.

PALAVRAS-CHAVE: Zea mays L.; Glycine max (L.) Merrill; acidez do solo.

proporcionando condições favoráveis ao crescimento do sistema radicular e absorção de água e nutrientes pelas plantas. No entanto, no SPD, a calagem é realizada em superfície, sem incorporação, e parcelada ao longo do tempo (Dalla Nora et al. 2013), promovendo efeitos superficiais, devido à baixa solubilidade do calcário e dos produtos de sua reação no solo (Rampim et al. 2011). Dessa forma, quando ocorrem subsolos ácidos, com baixo conteúdo de $\mathrm{Ca}^{2+}$ ou alto teor de $\mathrm{Al}^{3+}$, o crescimento do sistema radicular e, consequentemente, a absorção de água e

1. Trabalho recebido em jun./2014 e aceito para publicação em mar./2015 (http://dx.doi.org/10.1590/1983-40632015v4530301).

2. Universidade Federal do Pampa (Unipampa), Câmpus Itaqui, Itaqui, RS, Brasil.E-mails: renan_zandona@hotmail.com, amaurib@yahoo.com.br, gio_burg@hotmail.com,carol_fariasb@hotmail.com,marceloraulschmidt@hotmail.com. 
nutrientes podem ser comprometidos, principalmente em condições de deficiência hídrica.

Desde a década de 1990, o gesso tem sido utilizado no SPD para minimizar problemas de acidez, pela redução na toxidade por $\mathrm{Al}^{3+}$. $\mathrm{O}$ gesso reage com o $\mathrm{Al}^{3+}$ precipitando-o (Zambrosi et al. 2007) e fazendo com que ele fique em formas menos tóxicas $\left(\mathrm{AlSO}_{4}^{+}\right)$, além de aumentar os teores de $\mathrm{Ca}^{2+}$ e $\mathrm{S}$ no subsolo (Neis et al. 2010). Além disso, sua ação ocorre em maior profundidade que a do calcário, pois movimenta-se cerca de 150 vezes mais (Maschietto 2009). Assim, o gesso é considerado um condicionador de solo e pouco afeta o pH (Meurer et al. 2004), podendo compensar o efeito superficial do calcário, pois atua até no subsolo, sem a necessidade de incorporação (Caires et al. 2003).

Trabalhos têm demonstrado aumento na produtividade de grãos de milho, em razão da aplicação de gesso (Caires et al. 1999, Maschietto 2009), sendo associada ao aumento do $\mathrm{Ca}$ e $\mathrm{S}$ no tecido foliar, em Latossolo Vermelho-escuro distrófico de textura média (Caires et al. 1999). Caires et al. (2004), estudando a combinação de calcário e gesso em SPD, em Latossolo Vermelho distrófico de textura argilosa, verificaram incremento de $17 \%$ na produtividade de milho.

A aplicação de gesso não resultou em aumento da produtividade de grãos de soja em vários estudos (Caires et al. 1999, 2003 e 2006, Nogueira \& Melo 2003, Maschietto 2009). De acordo com Nogueira \& Melo (2003), a ausência de resposta da soja à aplicação de gesso está relacionada à quantidade de $\mathrm{S}$ proveniente da mineralização da matéria orgânica suficiente para suprir as necessidades da cultura. Caires et al. (2008) atribuíram a ausência de resposta da soja ao fato de o crescimento radicular não ser influenciado pelo $\mathrm{Al}^{3+}$, na ausência de déficit hídrico.

Há carência de estudos com a utilização de gesso agrícola e calcário associados à produtividade de milho e soja (Dalla Nora et al. 2013), no Rio Grande do Sul, onde, frequentemente, ocorre déficit hídrico, a exemplo da safra 2011/2012, em que a produtividade das culturas de milho e soja foi reduzida pelo déficit hídrico causado pelo fenômeno La Niña (Conab 2012).

Este trabalho objetivou avaliar a influência da aplicação de gesso agrícola, com e sem calcário, nos atributos químicos de um Latossolo Vermelho distrófico e na produtividade de milho e soja, em sistema plantio direto.

\section{MATERIAL E MÉTODOS}

Os experimentos foram realizados na safra 2012/2013, no município de Barra Funda (RS) (27055'56"S e 5331'58'W), em Latossolo Vermelho distrófico típico (Embrapa 2013), que apresentou $640 \mathrm{~g} \mathrm{~kg}^{-1}, 660 \mathrm{~g} \mathrm{~kg}^{-1}$ e $680 \mathrm{~g} \mathrm{~kg}^{-1}$ de argila, nas camadas de $0-10 \mathrm{~cm}, 10-20 \mathrm{~cm}$ e $20-40 \mathrm{~cm}$ de profundidade, respectivamente. Segundo a classificação de Köppen-Geiger, o clima é do tipo Cfa, subtropical úmido sem estação seca definida, com verões quentes (Peel et al. 2007). A precipitação pluvial, de junho de 2012 a março de 2013, é apresentada na Figura 1.

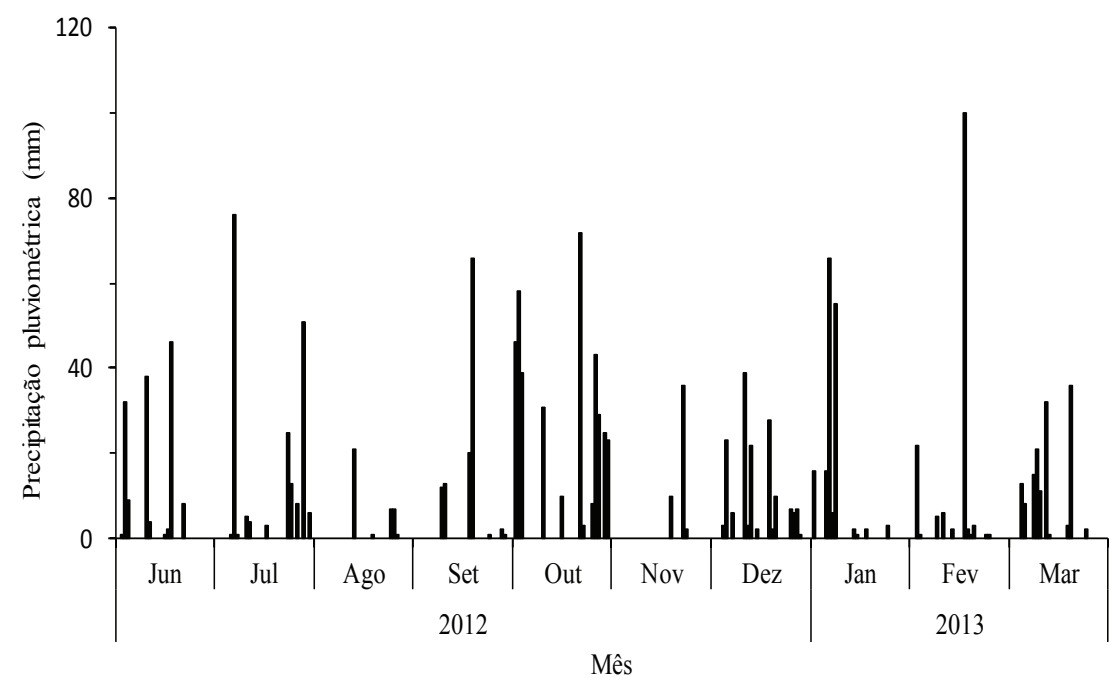

Figura 1. Precipitação pluvial (mm) durante o experimento, na safra 2012/2013 (Barra Funda, RS). 
Antes da instalação do experimento, o solo foi cultivado durante 13 anos em SPD, com aplicação de $2 \mathrm{t}$ ha ${ }^{-1}$ de calcário por triênio e rotação anual de culturas, sendo que a área estava dividida em 2 glebas (dois experimentos). Na gleba 1, foi semeado nabo forrageiro (Raphanus sativus L.) + aveia preta (Avena strigosa), no inverno, e milho (Zea mays L.), no verão; e, na gleba 2, trigo (Triticum aestivum), no inverno, e soja (Glycine max (L.) Merrill), no verão.

As culturas da gleba 1 foram rotacionadas com as da gleba 2, exceto no ano de 2012, em que o trigo foi substituído por aveia preta, antecedendo a soja. A aveia e o nabo forrageiro foram dessecados 70 dias antes da semeadura do milho e da soja. As análises químicas de caracterização do solo das áreas com as culturas do milho e da soja são apresentadas na Tabela 1.

No ano de instalação do experimento (2012), adotou-se o delineamento experimental inteiramente casualizado, com quatro repetições, tanto para o experimento com o milho (gleba 1), quanto para o experimento com a soja (gleba 2). O experimento com milho avaliou seis doses de gesso agrícola $\left(0 \mathrm{t} \mathrm{ha}^{-1}\right.$, $0,5 \mathrm{t} \mathrm{ha}^{-1}, 1 \mathrm{t} \mathrm{ha}^{-1}, 2 \mathrm{t} \mathrm{ha}{ }^{-1}, 4 \mathrm{t} \mathrm{ha}^{-1}$ e $\left.8 \mathrm{t} \mathrm{ha}^{-1}\right)(16 \%$ de enxofre e $24 \%$ de cálcio), com aplicação de $2 \mathrm{t} \mathrm{ha}^{-1}$ de calcário (PRNT 70), sendo suas parcelas formadas por seis linhas, totalizando $4,5 \mathrm{~m} \times 7 \mathrm{~m}\left(31,5 \mathrm{~m}^{2}\right)$. $\mathrm{O}$ experimento com soja foi instalado em esquema fatorial (6 x 2), com seis doses de gesso agrícola ( $0 \mathrm{t} \mathrm{ha}^{-1}, 0,5 \mathrm{t} \mathrm{ha}^{-1}, 1 \mathrm{t} \mathrm{ha}^{-1}, 2 \mathrm{t} \mathrm{ha}^{-1}, 4 \mathrm{tha}^{-1}$ e $\left.8 \mathrm{t} \mathrm{ha}^{-1}\right)$, com e sem aplicação de $2 \mathrm{t} \mathrm{ha}^{-1}$ de calcário, sendo suas parcelas formadas por seis linhas, totalizando $7 \mathrm{~m} \times 3 \mathrm{~m}\left(21 \mathrm{~m}^{2}\right)$. O calcário foi aplicado a lanço nas parcelas, em 02/06/2013, e o gesso em 23/06/2013, em ambos os experimentos.

A semeadura do milho (cultivar AG 8025 PRO) foi realizada em 02/09/2012, na densidade de 5 se- mentes por metro e espaçamento de $0,70 \mathrm{~m}$ entre as linhas. A adubação foi realizada segundo o manual de adubação e calagem para os Estados do RS e $\mathrm{SC}$, na expectativa de produtividade de $10,8 \mathrm{tha}^{-1}$ (SBCS 2004), sendo de $400 \mathrm{~kg} \mathrm{ha}^{-1}$ da fórmula 5-20-20 (N-P-K), na semeadura, e duas coberturas de $150 \mathrm{~kg} \mathrm{ha}^{-1}$ de ureia, quando as plantas estavam com 4 e 6 folhas.

A semeadura da soja (cultivar NS 6262 RR) foi realizada em 15/11/2012, na densidade de 14 sementes por metro e espaçamento de $0,50 \mathrm{~m}$ entre as linhas, para uma expectativa de produtividade de $4 \mathrm{t} \mathrm{ha}^{-1}$, sendo composta por $150 \mathrm{~kg} \mathrm{ha}^{-1} \mathrm{de} \mathrm{KCl}$ em cobertura, aos 15 dias antes da semeadura, e $300 \mathrm{~kg} \mathrm{ha}^{-1}$ da fórmula 2-20-18, na semeadura.

Amostras de solo compostas por 16 subamostras (quatro amostras em cada uma das quatro repetições) por tratamento e por profundidade (36 amostras) foram coletadas para análise química, realizada segundo Tedesco et al. (1995), após a colheita do milho $(02 / 02 / 2013)$ e da soja $(30 / 03 / 2013)$. As amostras foram coletadas nas camadas de 0-10 cm, $10-20 \mathrm{~cm}$ e $20-40 \mathrm{~cm}$ de profundidade, nos tratamentos com e sem aplicação de calcário, e nas doses de $0 \mathrm{t} \mathrm{ha}{ }^{-1}, 0,5 \mathrm{t} \mathrm{ha}^{-1}, 4 \mathrm{tha}^{-1}$ e $8 \mathrm{t} \mathrm{ha}^{-1}$ de gesso.

Foram avaliadas as produtividades de grãos de milho em área de $14 \mathrm{~m}^{2} \mathrm{e}$ de soja em área de $9,0 \mathrm{~m}^{2}$, colhendo-se as quatro fileiras centrais de cada parcela, cujos conteúdos de água, nos grãos, foram corrigidos para $12 \%$.

Os resultados foram submetidos à análise de variância e, quando o F foi significativo, realizou-se regressão, a $5 \%$, para avaliar o efeito das doses de gesso na produtividade de grãos de milho e de soja. Para os atributos químicos, foram apenas ajustadas equações polinomiais, visto que não houve repetição de campo.

Tabela 1. Atributos químicos do solo, antes da aplicação do calcário e do gesso, para as culturas do milho e da soja (Barra Funda, RS, safra 2012/2013).

\begin{tabular}{|c|c|c|c|c|c|c|c|c|c|c|c|}
\hline \multirow{2}{*}{ Cultura } & Camada & MO & \multirow{2}{*}{$\begin{array}{l}\mathrm{pH} \\
\mathrm{H}_{2} \mathrm{O}\end{array}$} & $\mathrm{Ca}$ & $\mathrm{Mg}$ & $\mathrm{P}$ & $\mathrm{K}$ & $\mathrm{H}+\mathrm{Al}$ & $\mathrm{Al}$ & CTC & V \\
\hline & $\mathrm{cm}$ & $\%$ & & $-\mathrm{cmol}$ & $\mathrm{L}^{-1}-$ & $-\mathrm{mg}$ & $\mathrm{L}^{-1}-$ & $-\mathrm{cmol}_{\mathrm{c}}$ & $\mathrm{L}^{-1}$ & $\mathrm{pH} 7$ & $\%$ \\
\hline \multirow{3}{*}{ Milho } & $0-10$ & 2,1 & 5,6 & 4,9 & 1,9 & 23,8 & 220 & 4,4 & 0,0 & 11,8 & 63 \\
\hline & $10-20$ & 2,0 & 5,5 & 3,7 & 1,6 & 6,8 & 120 & 4,9 & 0,0 & 11,0 & 53 \\
\hline & $20-40$ & 1,9 & 4,9 & 2,0 & 1,2 & 4,5 & 36 & 7,7 & 0,9 & 10,5 & 30 \\
\hline \multirow{3}{*}{ Soja } & $0-10$ & 2,0 & 5,4 & 4,9 & 1,9 & 10,1 & 172 & 4,4 & 0,1 & 11,7 & 55 \\
\hline & $10-20$ & 2,0 & 5,1 & 3,5 & 1,7 & 6,8 & 100 & 5,5 & 0,4 & 11,1 & 49 \\
\hline & $20-40$ & 1,8 & 4,9 & 2,7 & 1,3 & 8,4 & 80 & 6,9 & 0,9 & 10,8 & 37 \\
\hline
\end{tabular}




\section{RESULTADOS E DISCUSSÃO}

No solo sem aplicação de gesso agrícola e sem calcário, houve pouca alteração nos atributos químicos (Figuras 2, 3 e 4) e, nas áreas com aplicação de doses de gesso, houve pouca alteração do $\mathrm{pH}$ do solo (Figuras 2, 3a e 3b). O gesso é um sal neutro, que não possui capacidade de consumir prótons $\mathrm{H}^{+}$e aumentar o pH do solo (Maschietto 2009). Já a aplicação do calcário na superfície do solo aumentou o $\mathrm{pH}$ na camada superficial de 0-10 cm (Figuras 2 e 3b), em comparação à área sem aplicação de calcário (Figura 3a).

A aplicação de gesso resultou em acréscimos nos teores de $\mathrm{Ca}^{2+}$ no solo, na camada de $0-10 \mathrm{~cm}$ de profundidade, aos 9 meses após a aplicação (Figuras 2 e $4 b$ ). Houve incremento expressivo nos teores de $\mathrm{Ca}^{2+}$, na camada de $0-10 \mathrm{~cm}$, onde a dose de $8 \mathrm{t} \mathrm{ha}^{-1}$ de gesso foi aplicada com mais $2 \mathrm{t} \mathrm{ha}^{-1} \mathrm{de}$ calcário, resultando em aumento de $48 \%$ e $56 \%$, respectivamente, no experimento com milho e soja (Figuras 2 e 4b). Já no tratamento com gesso aplicado sem calcário, o aumento foi de $34 \%$. Além disso, quando o gesso foi aplicado associado ao calcário, o teor de Ca, na camada de 10-20 cm, ficou próximo a $5 \mathrm{cmo}_{c} \mathrm{~L}^{-1}$ (Figuras $2 \mathrm{e} 4 \mathrm{~b}$ ), aproximadamente $25 \%$ superior, quando comparado à área onde foi aplicado gesso sem calcário (Figura 4a), indicando a translocação vertical do Ca para essa camada. O mesmo comportamento foi obtido por Dalla Nora et al. (2013), na camada de 0-60 cm, com aplicação de $5 \mathrm{t} \mathrm{ha}^{-1}$ de gesso agrícola na superfície, indicando movimento vertical do $\mathrm{Ca}^{2+}$, no perfil de um Latossolo.

Caires et al. (2003) verificaram aumento superior a $100 \%$ no teor de $\mathrm{Ca}^{2+}$, na camada de 0-5 cm, com a aplicação de $9 \mathrm{t} \mathrm{ha}^{-1}$ de gesso, em Latosso Vermelho distrófico de textura argilosa. Também foi observada maior redistribuição de $\mathrm{Ca}^{2+}$ em profundidade, com a utilização do gesso. $\mathrm{O}$ incremento dos teores de $\mathrm{Ca}^{2+}$ em profundidade está relacionado com a disponibilidade e aplicação do nutriente, com a movimentação do $\mathrm{Ca}^{2+}$, que é influenciada pela infiltração de água no solo, e pela ligação com o ânion $\mathrm{SO}_{4}^{2-}$, que permite a movimentação até a subsuperfície (Costa 2011).

Os teores de $\mathrm{Mg}^{2+}$ no solo também aumentaram com a aplicação de gesso, nas camadas de 10-20 cm e 20-40 cm (Figuras 2 e 4). No entanto, houve redução na camada de $0-10 \mathrm{~cm}$ e aumento nas camadas inferiores, com destaque para a camada de $20-40 \mathrm{~cm}$, indicando maior mobilidade, em comparação ao $\mathrm{Ca}^{2+}$.
Resultados semelhantes foram encontrados por Dalla Nora et al. (2013), com redistribuição vertical do $\mathrm{Mg}^{2+}$ no perfil do solo. Tal fato é resultado da formação do par iônico $\mathrm{MgSO}_{4}$, que permite movimentação desse elemento no perfil do solo (Zambrosi et al. 2007, Maschietto 2009). O aumento dos teores de Mg trocável em profundidade, em relação ao Ca trocável, pode estar relacionado ao fato de o $\mathrm{Mg}$ ser menos fortemente retido no complexo de troca, devido ao seu maior raio hidratado e menor eletronegatividade, possibilitando maior movimentação no perfil.

Esse movimento vertical de $\mathrm{Mg}^{2+}$ no perfil do solo é benéfico à nutrição das plantas, desde que o teor crítico para a cultura seja mantido na camada superficial (Dalla Nora et al. 2013). Entretanto, é desejável a redistribuição e incremento em profundidade dos teores de cátions básicos, no SPD, para o decréscimo do impedimento químico ao desenvolvimento radicular e para aumentar a resistência ao déficit hídrico frequentes nos cultivos de milho e soja.

Os teores de $\mathrm{Al}^{3+}$ no solo foram baixos nas camadas de $0-10 \mathrm{~cm}$ e $10-20 \mathrm{~cm}$ (Figuras 2 e 3 ) e inferiores a $10 \%$ de saturação por $\mathrm{Al}^{3+}(\mathrm{m})$. No entanto, na camada de $20-40 \mathrm{~cm}$, em geral, o teor de $\mathrm{Al}^{3+}$ trocável foi superior ao das camadas superficiais. A aplicação de gesso diminuiu o teor de $\mathrm{Al}^{3+}$, porém em pequenas quantidades, possivelmente em razão do curto período de apenas 9 meses da aplicação do gesso. Isso indica que a área possui condições ideais para o desenvolvimento das culturas com maior concentração de raízes até $20 \mathrm{~cm}$ de profundidade, mas, na camada de $20-40 \mathrm{~cm}$, apresenta impedimento, em função da toxidez por $\mathrm{Al}^{3+}$. Resultados semelhantes foram encontrados por Costa (2011), em Latossolo Vermelho distroférrico de textura média, que observou diminuição dos teores de $\mathrm{Al}^{3+}$, na camada de 0-20 cm, aos 48 e 60 meses após a aplicação de gesso.

A redução nos teores de $\mathrm{Al}^{3+}$ tóxico, em decorrência da aplicação de gesso, ocorre pela precipitação de $\mathrm{Al}$ e formação de minerais (Adams \& Rawayfih 1977), ou, também, pela lixiviação de Al com o gesso, na forma de pares iônicos ou complexos $\mathrm{AlSO}_{4}^{+}$ (Pavan et al. 1984).

A CTC do solo aumentou na camada de 0-10 cm, após a aplicação de gesso agrícola e calcário (Figuras 2 e 3). Esse aumento é importante para a fertilidade do solo, pois proporciona aos coloides maior capacidade de reter cátions como o $\mathrm{Ca}^{2+}, \mathrm{Mg}^{2+}$ $\mathrm{e} \mathrm{K}^{+}$, nutrientes importantes para o crescimento das plantas. 

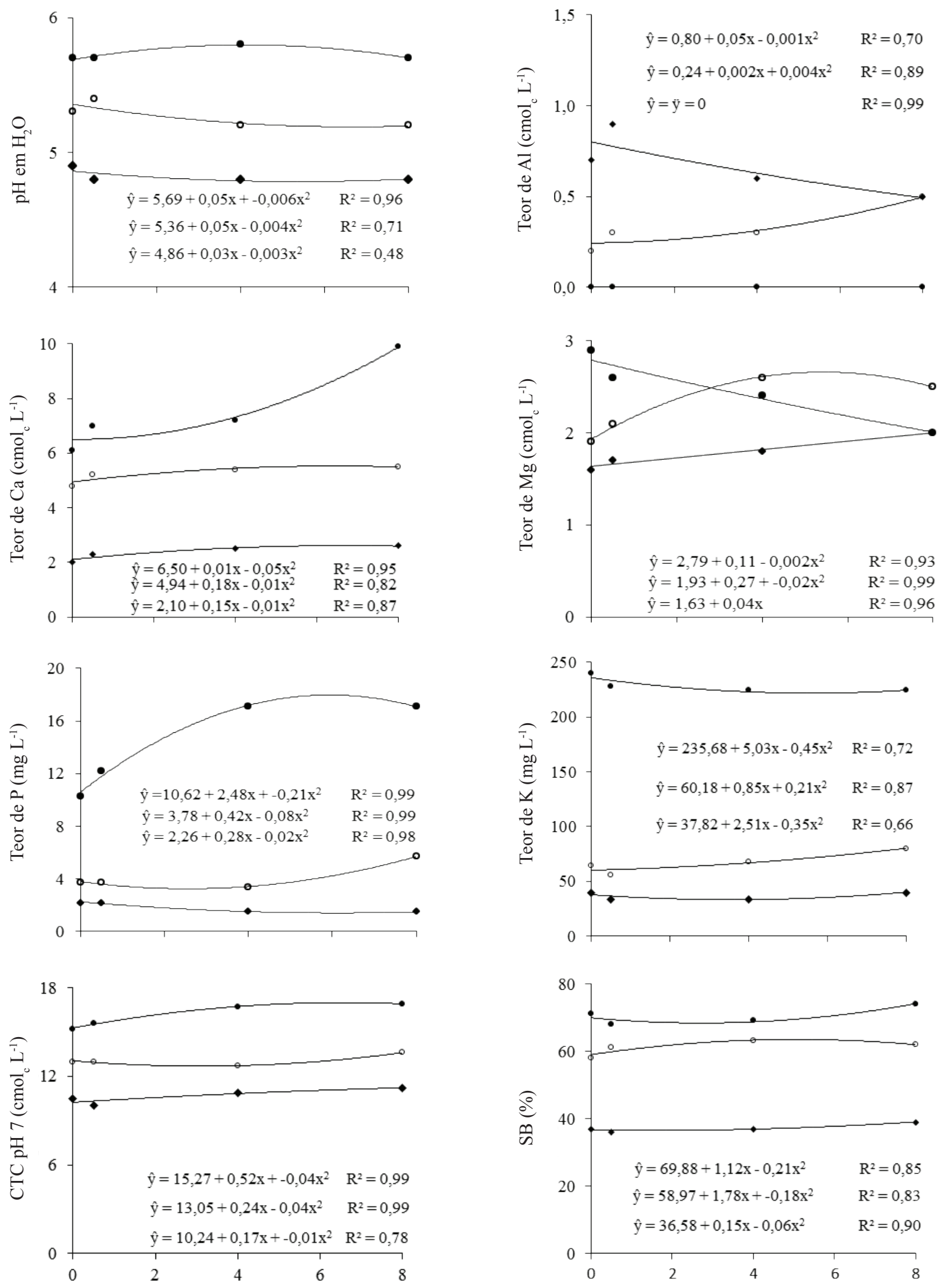

Dose de gesso $\left(\mathrm{t} \mathrm{ha}^{-1}\right)$

Figura 2. Atributos químicos em três camadas de solo, após a aplicação de gesso e calcário, na cultura do milho (Barra Funda, RS, safra 2012/2013). 


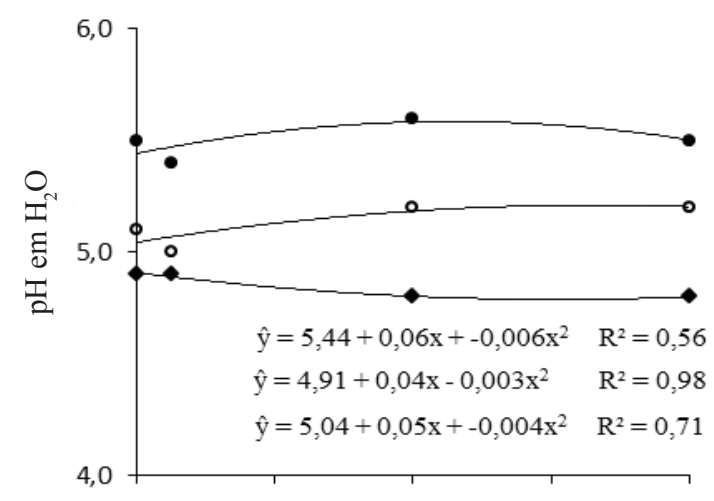

(a)
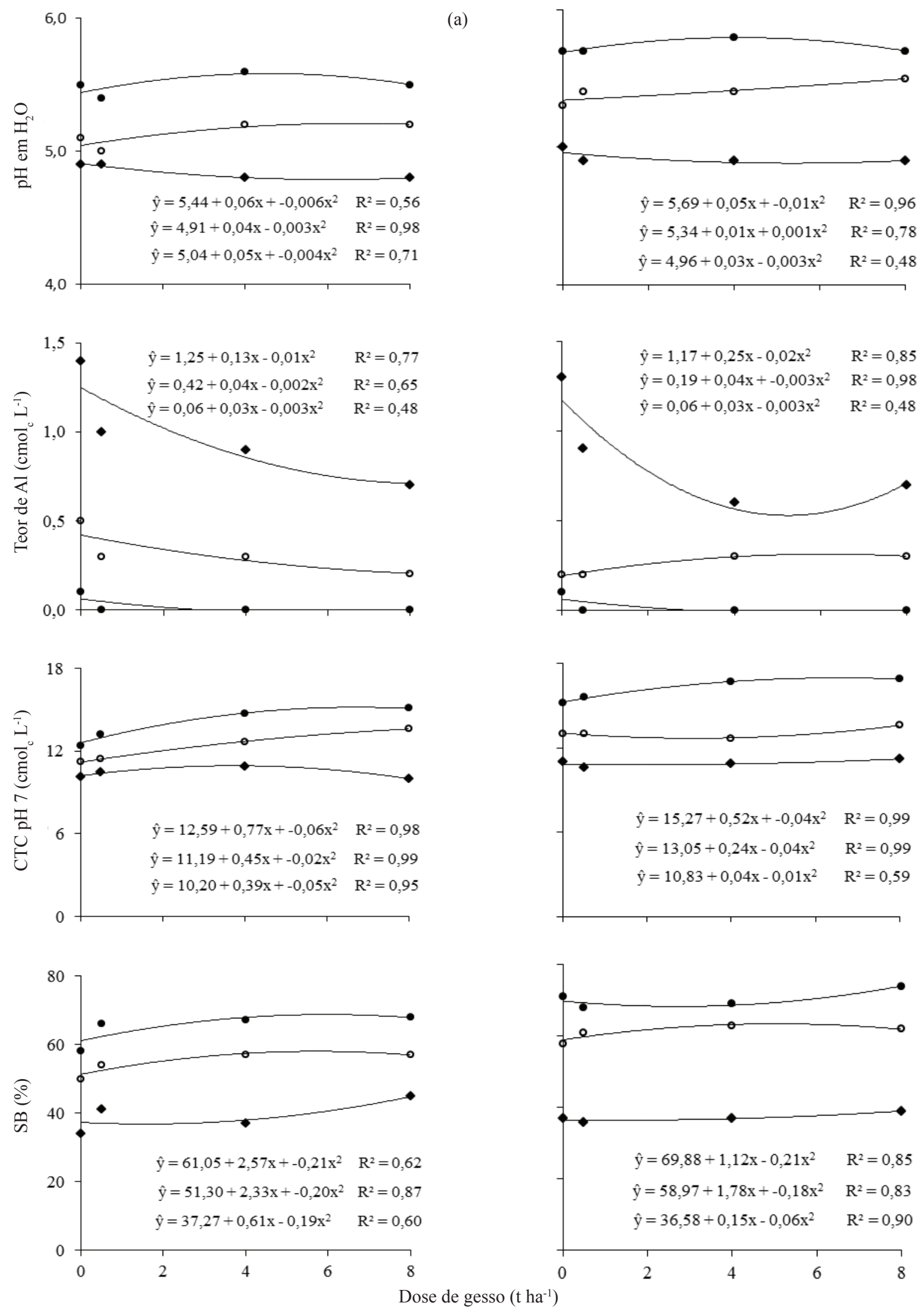

Figura 3. Atributos químicos em três camadas de solo, após a colheita da cultura da soja, com aplicação de gesso e sem calcário (a) e com aplicação de gesso e calcário (b) (Barra Funda, RS, safra 2012/2013). 


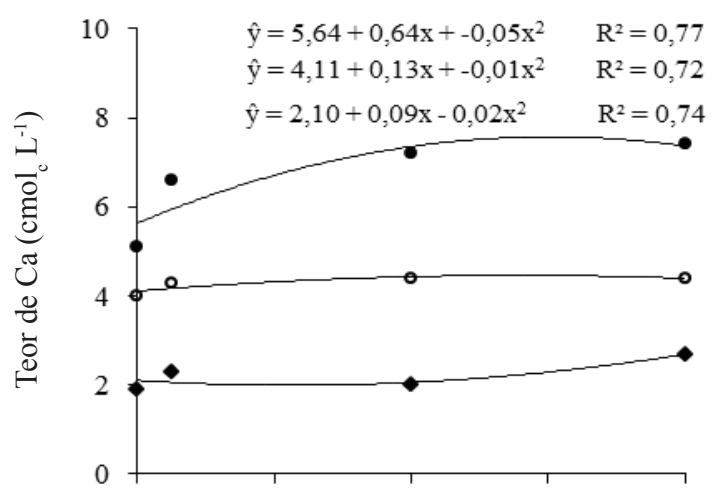

(a)

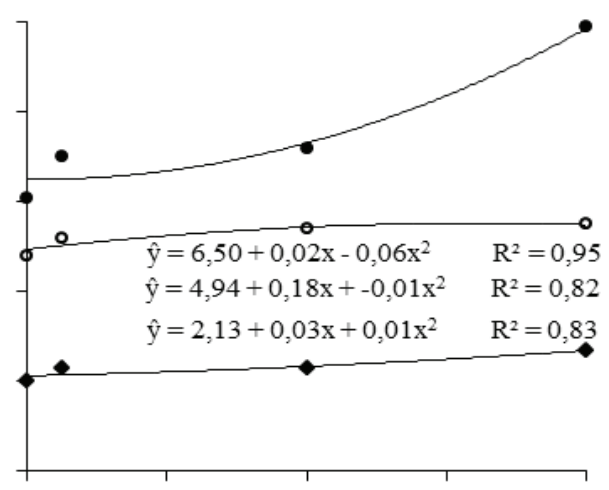

(b)
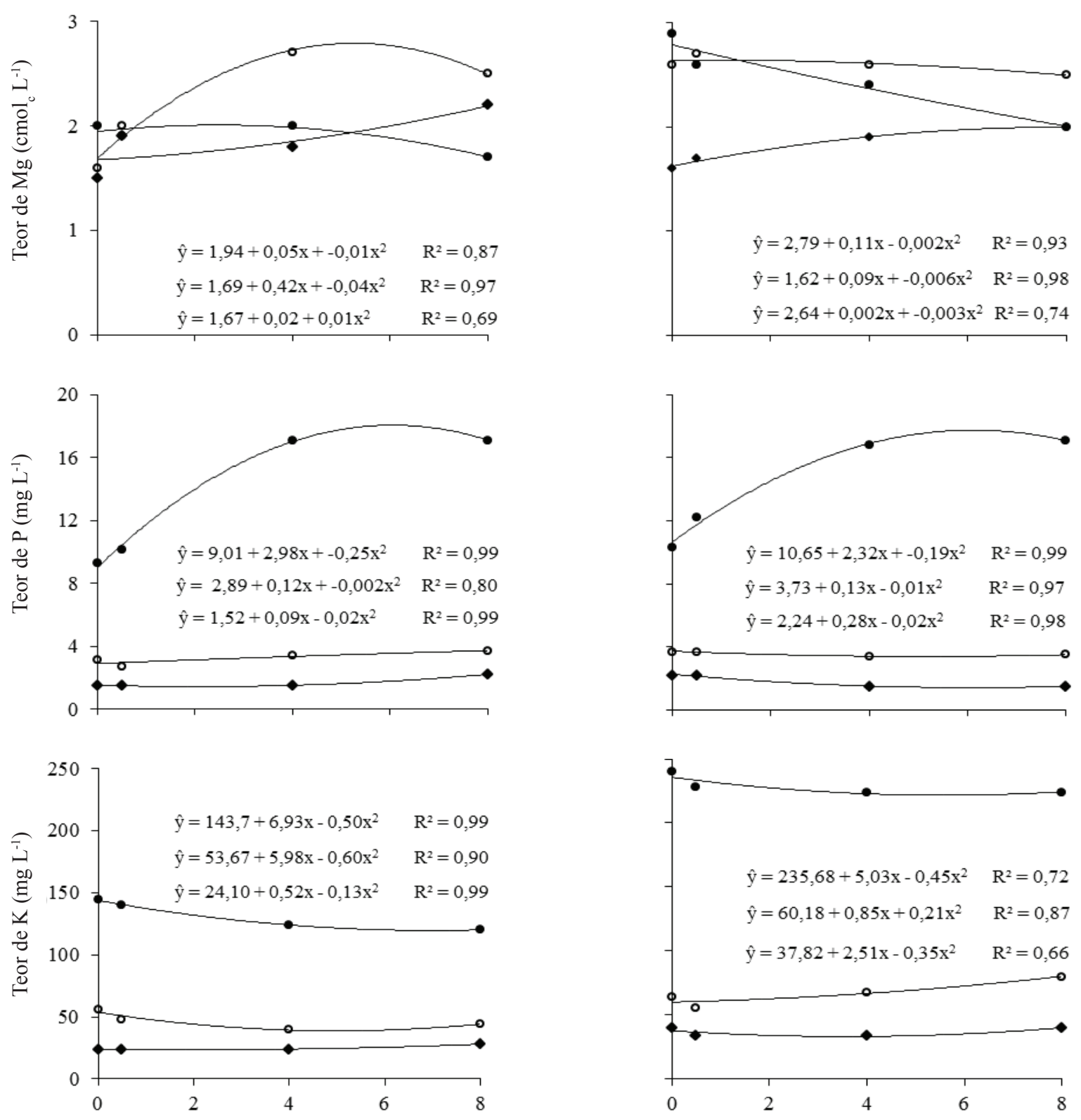

Dose de gesso $\left(\mathrm{t} \mathrm{ha}^{-1}\right)$

Figura 4. Atributos químicos em três camadas de solo, após a colheita da cultura da soja, com aplicação de gesso e sem calcário (a) e com aplicação de gesso e calcário (b) (Barra Funda, RS, safra 2012/2013). 
A melhoria nas características químicas do solo, com a aplicação isolada de gesso, promoveu aumento na produtividade de grãos da cultura do milho e da soja, com incremento de $9,3 \%$, para o milho, e de $11,4 \%$ e $11,3 \%$, respectivamente com e sem calcário $\left(2 \mathrm{t} \mathrm{ha}^{-1}\right)$, para a soja (Figura 5).

$\mathrm{O}$ gesso aumentou a produtividade de grãos de milho, mesmo na ausência de déficit hídrico, visto que o período mais crítico para a cultura (floração) ocorreu no mês de dezembro. Nessa época, ocorreu distribuição regular da pluviosidade suficiente para atender à demanda hídrica (Figura 1). Caires et al. (2011) também observaram incremento de $9 \%$ na produtividade de milho, na ausência de déficit hídrico, em Latossolo. Dessa forma, o aumento de produção de grãos de milho verificado neste estudo está relacionado com a melhoria dos atributos químicos do solo, como o incremento nos teores de $\mathrm{Ca}^{2+}$

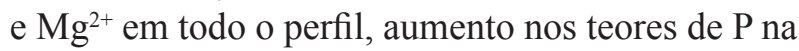
camada de $0-10 \mathrm{~cm}$ e decréscimo da saturação por $\mathrm{Al}^{3+}$ na camada subsuperficial.

A resposta da cultura do milho à aplicação de gesso foi maior até a dose de $2 \mathrm{t} \mathrm{ha}^{-1}$. Isso devido ao fato de a fertilidade do solo ter aumentado os teores de $\mathrm{Ca}^{2+} \mathrm{e} \mathrm{Mg}^{2+}$ nas camadas de 0-10 $\mathrm{cm}$ e $10-20 \mathrm{~cm}$ de profundidade, o que supriu as exigências da cultura e proporcionou altas produtividades.

A aplicação de calcário aumentou a produtividade de soja em todas as doses de gesso (Figura 5). A aplicação de gesso e calcário na cultura da soja possibilitou incremento de produtividade, possivel-

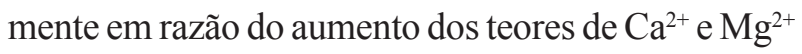
em todo o perfil de solo, juntamente com o aumento do $\mathrm{pH}\left(\mathrm{H}_{2} \mathrm{O}\right)$ na camada de $0-10 \mathrm{~cm}$, para valores superiores a 5,5, próximos ao ideal para a cultura da soja. Além disso, a aplicação de calcário aumentou o pH do solo para 5,5, na camada de $10-20 \mathrm{~cm}$, e reduziu os teores de $\mathrm{Al}^{3+}$, na camada de $20-40 \mathrm{~cm}$ (Figura 3), propiciando condições químicas mais favoráveis ao desenvolvimento radicular, absorção de água e nutrientes.

$\mathrm{Na}$ cultura da soja, a maior resposta foi obtida com $2 \mathrm{t} \mathrm{ha}^{-1}$ de gesso e, a partir dessa dose, o aumento de produtividade foi pouco expressivo. Isso é atribuído à melhoria das características químicas do solo (Figuras 3 e 4). Resultados semelhantes foram obtidos por Costa (2011), em Latossolo Vermelho distroférrico de textura média. Estudando a melhor dose de calcário com e sem aplicação de gesso, o autor verificou que a maior produtividade na área foi obtida com a aplicação de $2,1 \mathrm{t} \mathrm{ha}^{-1}$ de gesso.

$\mathrm{Na}$ soja, o efeito do gesso foi mais pronunciado, em razão da ausência de chuva no estádio de florescimento da cultura, no final do mês de janeiro (Figura 1). A melhora na fertilidade do solo em subsuperfície possivelmente permitiu melhor desenvolvimento radicular e maior tolerância ao déficit hídrico. Sousa et al. (2005) também obtiveram incrementos de produtividade da ordem de $0,3 \mathrm{tha}^{-1}$, para a cultura da soja, em Latossolo argiloso, com a aplicação de gesso agrícola, quando ocorreram veranicos na época mais crítica para a cultura (floração).
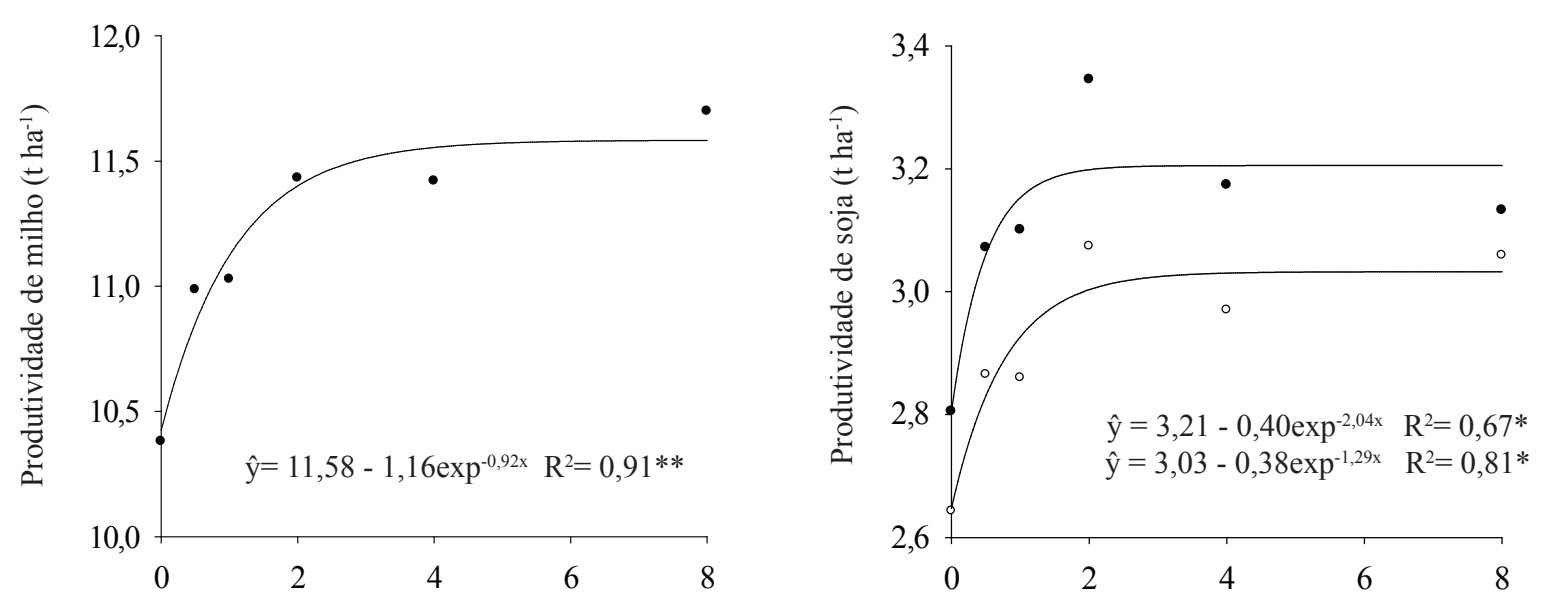

Dose de gesso $\left(\mathrm{t} \mathrm{ha}^{-1}\right)$

Figura 5. Produtividade de grãos de milho e soja, em função da dose de gesso, com (•) e sem (o) calcário (Barra Funda, RS, safra 2012/2013). ** e * Significativo a 1\% e 5\%, respectivamente. 
Segundo Nuernberg et al. (2005), quando o gesso é aplicado ao solo, a maior resposta sob condições de deficiência hídrica está no maior crescimento radicular. Alguns estudos destacam que, sob condições de distribuição regular de chuvas, não há resposta à aplicação de gesso (Caires et al. 1999, 2003 e 2006, Maschietto 2009). Além disso, Caires et al. (2008) observaram que, em anos de déficit hídrico, o $\mathrm{Al}^{3+}$ presente no solo prejudicou severamente o desenvolvimento radicular e a produtividade das culturas.

\section{CONCLUSÕES}

1. O gesso agrícola aumenta os teores de $\mathrm{Ca}^{2+}$, re-

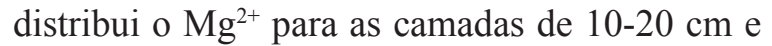
20-40 $\mathrm{cm}$ e diminui os teores de $\mathrm{Al}^{3+}$ na camada de $20-40 \mathrm{~cm}$.

2. A aplicação de gesso e calcário em superfície aumenta a capacidade de troca de cátions, na camada de $0-10 \mathrm{~cm}$ de profundidade.

3. O gesso agrícola aumenta a produtividade de grãos de milho e de soja, com resposta até a dose de $2 \mathrm{t} \mathrm{ha}^{-1}$, com incrementos de $9,3 \%$, para o milho, e de $11,4 \%$ e $11,3 \%$, respectivamente com e sem calcário, para a soja.

\section{REFERÊNCIAS}

ADAMS, F.; RAWAYFIH, Z. Basalumite and alumite: a possible cause of sulfate retention by acid soils. Soil Science Society of America Journal, Madison, v. 41, n. 4, p. 686-692, 1977.

CAIRES, E. F. et al. Alterações químicas do solo e resposta da soja ao calcário e gesso aplicados na implantação do sistema plantio direto. Revista Brasileira de Ciência do Solo, Viçosa, v. 27, n. 2, p. 275-286, 2003.

CAIRES, E. F. et al. Alterações químicas do solo e resposta do milho à calagem e aplicação de gesso. Revista Brasileira de Ciência do Solo, Viçosa, v. 28, n. 1, p. 125136, 2004.

CAIRES, E. F. et al. Effects of soil acidity amelioration by surface liming on no-till corn, soybean, and wheat root growth and yield. European Journal of Agronomy, Amsterdam, v. 28, n. 1, p. 57-64, 2008.

CAIRES, E. F. et al. Produção de milho, trigo e soja em função das alterações das características químicas do solo pela aplicação de calcário e gesso na superfície, em sistema plantio direto. Revista Brasileira de Ciência do Solo, Viçosa, v. 23, n. 2, p. 315-327, 1999.
CAIRES, E. F. et al. Soybean yield and quality as a function of lime and gypsum applications. Scientia Agricola, Piracicaba, v. 63, n. 4, p. 370-379, 2006.

CAIRES, E. F. et al. Use of gypsum for crop grain production under a subtropical no-till cropping system. Agronomy Journal, Madison, v. 103, n. 6, p. 1804-1814, 2011.

COMPANHIA NACIONAL DE ABASTECIMENTO (Conab). Acompanhamento da safra brasileira (grãos - safra 2011/2012). 2012. Disponível em: <http://www.conab.gov. br/OlalaCMS/uploads/arquivos/12_03_13_11_04_08_ boletim_marco_2012.pdf>. Acesso em: 24 nov. 2014 .

COSTA, C. H. M. Efeito residual da aplicação superficial de calcário e gesso nas culturas de soja, aveia-preta e sorgo granifero. 2011. 80 f. Dissertação (Mestrado em Agricultura) - Universidade Estadual Paulista, Botucatu, 2011.

DALLA NORA, D. D. et al. Gesso: alternativa para redistribuir verticalmente nutrientes no perfil do solo sob sistema plantio direto. Revista Plantio Direto, Passo Fundo, v. 133, n. 1, p. 8-20, 2013.

EMPRESA BRASILEIRA DE PESQUISA AGROPECUÁRIA (Embrapa). Sistema brasileiro de classificação de solos. 3. ed. Rio de Janeiro: Embrapa Solos, 2013.

FAGERIA, N. K. Efeito da calagem na produção de arroz, feijão, milho e soja em solo de Cerrado. Pesquisa Agropecuária Brasileira, Brasília, DF, v. 36, n. 11, p. 14191424, 2001.

FEDERAÇÃO BRASILEIRA DE PLANTIO DIRETO NA PALHA (Febrapdp). Evolução da área de plantio direto no Brasil. 2012. Disponível em: <http://www. febrapdp.org.br/ download/PD_Brasil_2013.I.pdf>. Acesso em: 24 nov. 2014.

MASCHIETTO, E. H. G. Gesso agrícola na produção de milho e soja em solo de alta fertilidade e baixa acidez em subsuperficie em plantio direto. 2009. 56 f. Dissertação (Mestrado em Agricultura) - Universidade Estadual de Ponta Grossa, Ponta Grossa, 2009.

MEURER, E. J.; RHENHEIMER, D.; BISSANI, C. A. Fenômeno de sorção em solos. In: MEURER, J. E. (Ed.). Fundamentos de química do solo. 2. ed. Porto Alegre: Gênesis, 2004. p. 131-179.

NEIS, L. et al. Gesso agrícola e rendimento de grãos de soja na região do sudoeste de Goiás. Revista Brasileira de Ciência do Solo, Viçosa, v. 34, n. 2, p. 409-416, 2010.

NOGUEIRA, M. A.; MELO, W. J. Enxofre disponível para a soja e a atividade de arilsulfatase em solo tratado com gesso agrícola. Revista Brasileira de Ciência do Solo, Viçosa, v. 27, n. 4, p. 655-663, 2003. 
NUERNBERG, N. J.; RECH, T. D.; BASSO, C. Usos do gesso agrícola. 2. ed. Florianópolis: Epagri, 2005. (Boletim técnico, 122).

PAVAN, M. A.; BINGHAM, F. T.; PRATT, P. F. Redistribution of exchangeable calcium, magnesium, and aluminum following lime and gypsum applications to a Brazilian Oxisol. Soil Science Society of America Journal, Madison, v. 48, n. 1, p. 33-38, 1984.

PEEL, M. C.; FINLAYSON, B. L.; MCMAHON, T. A. Updated world map of the Köppen-Geiger climate classification. Hydrology and Earth System Science, Göttingen, v. 11, n. 5, p. 1633-1644, 2007.

RAMPIM, L. et al. Atributos químicos de solo e resposta do trigo e da soja ao gesso em sistema semeadura direta. Revista Brasileira de Ciência do Solo, Viçosa, v. 35, n. 5, p. 1687-1698, 2011.
SOUSA, D. M. G.; LOBATO, E.; REIN, T. A. Uso do gesso em solos do Cerrado. Planaltina, DF: Embrapa, 2005. (Circular técnica, 32).

SOCIEDADE BRASILEIRA DE CIÊNCIA DO SOLO (SBCS). Manual de adubação e calagem para os Estados do Rio Grande do Sul e Santa Catarina. 10. ed. Porto Alegre: SBCS, 2004.

TEDESCO, M. J. et al. Análises de solo, plantas e outros materiais. Porto Alegre: UFRGS, 1995. (Boletim técnico, 5).

ZAMBROSI, F .C. B.; ALLEONI, L. R. F.; CAIRES, E. F. Aplicação de gesso agrícola e especiação iônica da solução de um Latossolo sob sistema plantio direto. Ciência Rural, Santa Maria, v. 37, n. 1, p. 110-117, 2007. 